\title{
Forced response of atmospheric oscillations during the last millennium simulated by a climate system model
}

\author{
MAN WenMin $^{1,2^{*}} \&$ ZHOU TianJun ${ }^{1}$ \\ ${ }^{1}$ The State Key Latoratory of Numerical Modeling for Atmospheric Sciences and Geophysical Fluid Dynamics, Institute of Atmospheric Physics, \\ Chinese Academy of Sciences, Beijing 100029, China; \\ ${ }^{2}$ Graduate University of Chinese Academy of Sciences, Beijing 100029, China
}

Received March 7, 2011; accepted June 16, 2011

\begin{abstract}
Variations in global atmospheric oscillations during the last millennium are simulated using the climate system model FGOALS_gl. The model was driven by reconstructions of both natural forcing (solar variability and volcanic aerosol) and anthropogenic forcing (greenhouse gases and sulfate aerosol). The model results are compared against proxy reconstruction data. The reconstructed North Atlantic Oscillation (NAO) was out of phase with the Pacific Decadal Oscillation (PDO) in the last millennium. During the Medieval Warm Period (MWP), the NAO was strong while the PDO was weak. During the Little Ice Age (LIA), the NAO was weak while the PDO was strong. A La Niña-like state prevailed in the MWP, while an El Niño-like state dominated in the LIA. This phenomenon is particularly obvious in the 15th, 17th and 19th centuries. Analysis of the model output indicates that the NAO was generally positive during 1000-1400 AD and negative during 1650-1900 AD. There is a discrepancy between the simulation and reconstruction during 1400-1650 AD. The simulated PDO generally varies in parallel with the reconstruction, which has a negative phase during the MWP and a positive phase during the LIA. The correlation coefficient between the reconstruction and simulation is 0.61 , and the correlation is statistically significant at the $1 \%$ level. Neither the La Niña-like state of the MWP nor the El Niño-like state of the LIA is reproduced in the model. Both the reconstructed and the simulated Antarctic Oscillations had a negative phase in the early period of the last millennium and a positive phase in the late period of the last millennium. The Asian-Pacific Oscillation was generally strong during the WMP and weak during the LIA, and the correlation coefficient between the simulation and reconstruction is 0.50 for the period 1000-1985 AD. The analysis suggests that the specified external forcings significantly affected the evolution of atmospheric oscillation during the last millennium.
\end{abstract}

millennial climate, atmospheric oscillation, external forcing, climate system model

Citation: Man W M, Zhou T J. Forced response of atmospheric oscillations during the last millennium simulated by a climate system model. Chinese Sci Bull, 2011, 56: 3042-3052, doi: 10.1007/s11434-011-4637-2

Global atmospheric circulations feature four atmospheric oscillations: the North Atlantic Oscillation (NAO); the North Pacific Oscillation, which is strongly associated with the Pacific Decadal Oscillation (PDO); the Southern Oscillation; and the Antarctic Oscillation (AAO). Since the atmospheric oscillations are considered the dominant circulation patterns for regional climate change, studies on the variations of atmospheric oscillation will improve our understanding of the physical processes that determine regional climate and also the mechanism of natural climate variability [1].

*Corresponding author (email: manmenmin@mail.iap.ac.cn)
Progress has been made in recent years in reconstructing long-term atmospheric oscillation time series using climate proxy data. For example, the mean $\delta^{18} \mathrm{O}$ values for Palmyra corals suggest that there was a La Niña-like condition in the 12th-13th centuries when the climate was relatively warm, while there was an El Niño-like condition in the cold 17th century [2]; there were strong NAO and weak PDO states during the Medieval Warm Period (MWP), while the situation was quite the opposite during the Little Ice Age (LIA) $[3,4]$.

Chinese scientists have made great efforts to study climate change over East Asia from the perspective of atmos- 
pheric oscillations. For example, Fu and Zeng [5] found that there was a close lag-correlation between the winter NAO index and the drought/flood (D/F) index (a five-grade category index for summer rainfall) over East China during 1470-1999 AD; Shen et al. [6] used the dataset of the D/F index commencing in $1470 \mathrm{AD}$ to reconstruct the annual PDO index and found that the PDO was a robust feature of North Pacific climate variability throughout the whole period, and there was excessive (deficient) precipitation along the Yangtze River Valley during the positive (negative) phases of the PDO. These previous studies have enriched our understanding of long-term climate variability over East Asian regions.

Climate models have been useful tools in studies of millennial climate change. A comparison of model simulation with reconstruction data would improve our understanding of the physical processes and underlying mechanisms of long-term climate variability [7]. Many climate modeling centers around the world have begun such millennial simulations using fully coupled climate system models [8-12]. Since the fluctuation of radiative forcing during the last millennium has been relatively small, and there are large uncertainties in the proxy data, the simulations and reconstructions are generally less consistent at regional scales than at global scales [13].

In this study, global atmospheric oscillations during the last millennium are simulated with a coupled climate system model developed by the State Key Laboratory of Numerical Modeling for Atmospheric Sciences and Geophysical Fluid Dynamics (LASG) at the Institute of Atmospheric Physics (IAP), Chinese Academy of Sciences (hereafter LASG/IAP). The main motivation of this study is to address how the atmospheric oscillations responded to the specified external forcings during the last millennium.

\section{Model and data description}

\subsection{Model description}

The coupled model used in this study is the fast version of the LASG/IAP Flexible Global Ocean-Atmosphere-LandSea ice model (FGOALS), which employs a low-resolution version of the Grid Atmospheric Model of IAP/LASG (GAMIL) as its atmospheric component and thus is referred as FGOALS_gl (the "l" of FGOALS_gl standing for the low resolution). The low-resolution version of GAMIL has a $72 \times 40$ weighted equal-area mesh, which corresponds to approximately a $5^{\circ}$ (longitude) $\times 4.5^{\circ}$ (latitude) grid, with 26 vertical levels for the sigma coordinate. The formulations of the physical parameterizations of the model are identical to those of the National Center for Atmospheric Research Community Atmosphere Model (NCAR CAM2). The oceanic component of FGOALS is the LASG/IAP Climate Ocean Model (LICOM), which has horizontal resolution of $1.0^{\circ} \times 1.0^{\circ}$ and 30 levels in the vertical direction. In addition, both the land and sea ice components of the model are derived from the NCAR Community Climate System Model (NCAR CCSM2). The four components are coupled using the NCAR CCSM2 coupler. There is no correction of the heat and freshwater fluxes exchanged at the interfaces among the atmosphere, ocean, sea ice, and land during coupled integrations. For details of the coupled model, the reader is referred to Zhou et al. [14]. The model has shown reasonable performance in simulating the climate of the last millennium [15-19]. There is no significant long-term drift in the 1000-year preindustrial control run, and the model captures major features of the internal modes of the El NiñoSouthern Oscillation (ENSO) and NAO [14,15]. The cooling of the LIA is found to be reasonably reproduced by FGOALS_gl when comparing with reconstruction data, demonstrating the dominant role of natural changes in solar irradiance in the change of the LIA climate [16-18]. In addition, the FGOALS_gl model reasonably captures the main characteristics of temperature change in the 20th century, especially at global, hemispheric, and continental scales [19].

\subsection{Experimental design and forcing data}

A 100-year control run is firstly carried out under external forcing conditions for 1000 AD. Starting with the initial oceanic conditions derived from a 500-year spin-up integration for present-day conditions [20], the simulation spanning the period 1000-1999 AD was conducted using the climate system model FGOALS_gl. The model is driven by reconstructions of natural forcing (solar activity and volcanic aerosols) and anthropogenic forcing (greenhouse gas emissions and sulfate aerosols). Both the solar radiation and volcanic forcing data are taken from Crowley [21]. The greenhouse gas concentration data $\left(\mathrm{CO}_{2}, \mathrm{CH}_{4}\right.$ and $\left.\mathrm{N}_{2} \mathrm{O}\right)$ are taken from Ammann et al. [22]. The effective solar radiation, which represents the sum of solar forcing and the radiative effects of volcanic aerosols, is strong during the MWP and weak during the LIA. The model experiment was described in detail by Zhang [23].

\subsection{Definitions of the atmospheric oscillations}

Following Hurrell et al. [24], the NAO index is defined as the difference in sea-level pressure (SLP) between the Azores high at $35^{\circ} \mathrm{N}, 10^{\circ} \mathrm{W}-10^{\circ} \mathrm{E}$ and the Icelandic low at $65^{\circ} \mathrm{N}, 30^{\circ}-10^{\circ} \mathrm{W}$ :

$$
\mathrm{NAO} \text { index }=\mathrm{SLP}_{35^{\circ} \mathrm{N}, 10^{\circ} \mathrm{W}-10^{\circ} \mathrm{E}}-\mathrm{SLP}_{65^{\circ} \mathrm{N}, 30^{\circ} \mathrm{W}-10^{\circ} \mathrm{W}} .
$$

Following Mantua et al. [25], the PDO index is defined as the sea surface temperature (SST) averaged over the central North Pacific region $22.5^{\circ} \mathrm{N}-57.5^{\circ} \mathrm{N}, 152.5^{\circ} \mathrm{E}-132.5^{\circ} \mathrm{W}$ :

$$
\mathrm{PDO} \text { index }=\mathrm{SST}_{22.5^{\circ} \mathrm{N}-57.5^{\circ} \mathrm{N}, 152.5^{\circ} \mathrm{E}-132.5^{\circ} \mathrm{W}} \text {. }
$$

The Niño-3 index is calculated as the SST averaged over 
the tropical East Pacific region $5^{\circ} \mathrm{S}-5^{\circ} \mathrm{N}, 90^{\circ}-150^{\circ} \mathrm{W}$ [26]:

$$
\text { Nino-3 index }=\mathrm{SST}_{5^{\circ} \mathrm{S}-5^{\circ} \mathrm{N}, 90^{\circ} \mathrm{W}-150^{\circ} \mathrm{W}} \text {. }
$$

Following Gong and Wang [27], the AAO index is defined as the difference in zonal mean SLP between $40^{\circ} \mathrm{S}$ and $65^{\circ} \mathrm{S}$ :

$$
\mathrm{AAO} \text { index }=\mathrm{SLP}_{40^{\circ} \mathrm{S}, 180^{\circ} \mathrm{W}-180^{\circ} \mathrm{E}}-\mathrm{SLP}_{65^{\circ}, 180^{\circ} \mathrm{W}-180^{\circ} \mathrm{E}} .
$$

In addition to the four global atmospheric oscillations, we further examine variations in the Asian-Pacific Oscillation (APO), which was defined as the zonal thermal contrast between the Asian continent and the Pacific Ocean by Zhao et al. [28]:

$$
\text { APO index }=T_{15^{\circ}-50^{\circ} \mathrm{N}, 60^{\circ}-120^{\circ} \mathrm{E}}-T_{15^{\circ}-50^{\circ} \mathrm{N}, 180^{\circ}-120^{\circ} \mathrm{W}} .
$$

\subsection{Reconstruction data}

A number of reconstructed atmospheric oscillation series are used in model comparisons.

(1) The NAO series commencing in $1050 \mathrm{AD}$ is reconstructed from both tree-ring records in Morocco and stalagmite records in Scotland [3].

(2) The PDO index for 993-1996 AD is constructed from tree-ring records in southwestern North America and Canada [4].

(3) The first half of the El Niño series is derived from drought events of the River Nile and the second half of the series is from rainfall records for South America. Diaz et al. [29] analyzed this series using the singular spectrum method and synthesized the singular spectrum coefficients of two bands (25-150 years and 11-25 years) as an ENSO series, which is used in this study.

(4) The AAO series is depicted with the rainfall conditions by taking the value of $\delta^{13} \mathrm{C}$ for lake sediments in the eastern Andes [30].

(5) The APO series is reconstructed from both the MayAugust mean air temperature at Beijing Shihua Cave $\left(39^{\circ} 47^{\prime} \mathrm{N}, 115^{\circ} 56^{\prime} \mathrm{E}\right)$ and the PDO index for $993-1985 \mathrm{AD}$ [31].

\section{Results}

\subsection{NAO}

The NAO is one of the most prominent atmospheric circulation modes over the North Atlantic sector. It is an oscillation between the Azores high and the Icelandic low. The NAO has a large climatic effect over Europe and North America. In addition, it modulates the climate over remote regions, such as East Asia. A number of proxy data based on tree rings and ice cores are used to reconstruct the NAO series for the past several hundred years [32-34]. On the basis of these reconstructed series, pentadecadal (50-70 years) and bidecadal bands have been proposed as dominant periods for the NAO.

The simulation and reconstruction of winter NAO variations during the last millennium are compared in Figure 1. The anomalies are calculated relative to the millennial mean. To emphasize low-frequency variations, a 31-year low-pass filter has been applied to both time series. The reconstructed NAO series features a persistent positive phase in the MWP and a weakening during the LIA, and the period of weakest NAO during the last millennium is $1750-1800$ AD. The simulation could generally reproduce the positive value during 1000-1400 AD. However, the sustained weakening in the following centuries is not evident in the simulation, especially for 1400-1650 AD. Using a general circulation model, Shindell et al. [35] found that the NAO shifts toward the low-index state as solar irradiance decreases, which leads to colder winter temperatures over the Northern Hemisphere continents. It should be noted that the mismatches between the simulation and reconstruction may be partly due to uncertainties in the station-based proxy data.

To reveal the dominant time scales of the NAO during the last millennium, the power spectra for the reconstructed and simulated NAO series are calculated and shown in Figure 2. The spectrum of the reconstructed NAO series has pronounced peaks at 200, 80 and 50 years (Figure 2(a)). Prominent peaks at 200,110, 70 and 50 years are seen in the simulation (Figure 2(b)), which correspond well to the significant spectral peaks derived from effective radiative forcing at around 200, 120, 90, 70 and 50 years (Figure $2(\mathrm{c}))$. The coherence of spectral peaks suggests that effective radiative forcing played a significant role in the decadalcentennial NAO changes in the last millennium.

\subsection{PDO}

The PDO is a long-lived ENSO-like pattern of Pacific climate variability. It has opposite SST anomalies between the North Pacific and the eastern tropical Pacific. As the important context of decadal climate variations, the PDO can affect the stability of monsoon-ENSO relationships [36,37]. Additionally, previous studies indicated that the PDO considerably affects climate over East Asian regions. During the warm phases of the PDO (when the North Pacific has cold SST anomalies and the eastern tropical Pacific has warm SST anomalies), significant positive SLP anomalies prevail over the East Asian continent, which corresponds to a weak East Asia summer monsoon (EASM) and is generally accompanied by excessive precipitation along the Yangtze River Valley and deficient precipitation in both North and South China. The regimes are the opposite in the cold phases of the PDO [38].

The low-pass filtered PDO series for the reconstruction and simulation are shown in Figure 3. The reconstructed PDO was out of phase with the reconstructed NAO during the last millennium. The PDO was weak during the MWP 

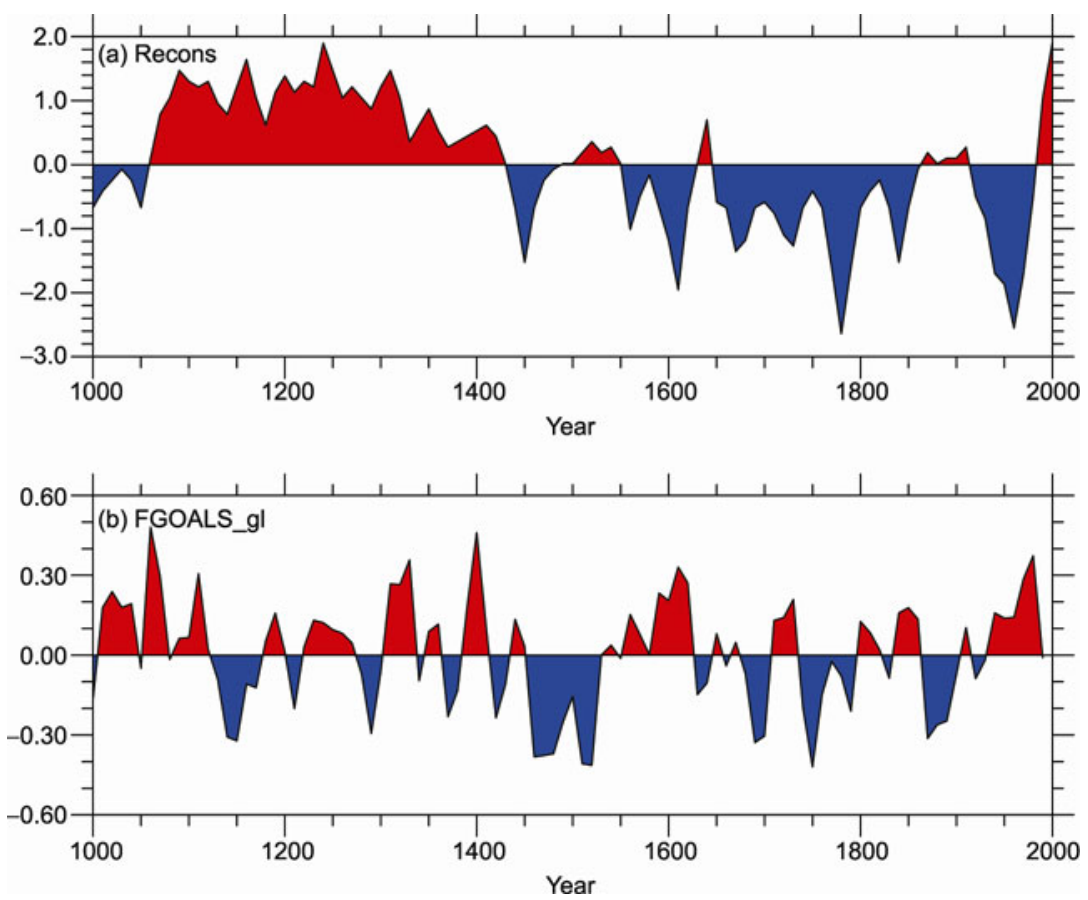

Figure 1 NAO variations during the last millennium derived from (a) reconstruction and (b) model simulation. The time series have been smoothed with a 31-year low-pass filter. The anomalies were calculated relative to the millennial mean.
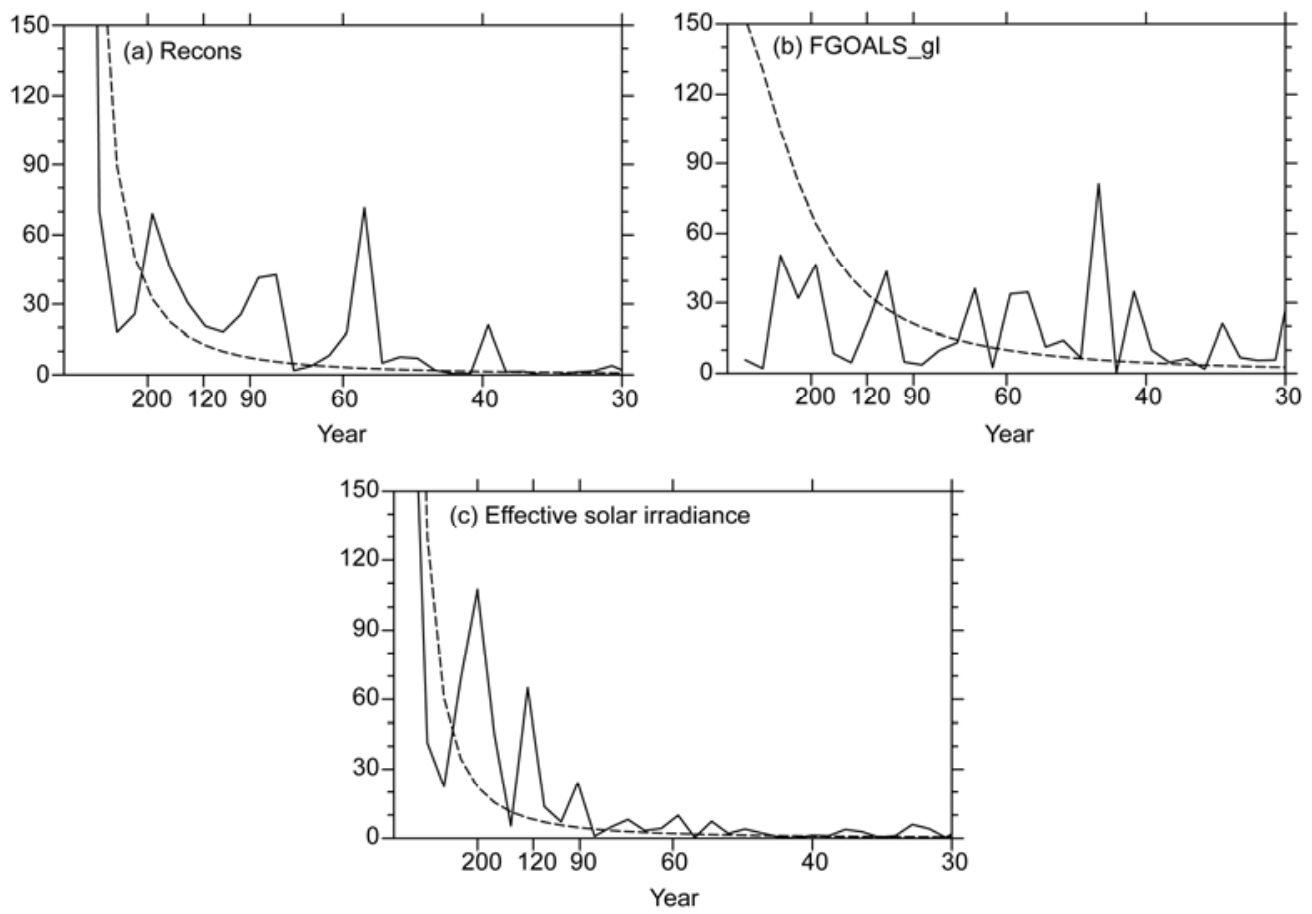

Figure 2 Power spectra of the NAO index derived from (a) reconstruction and (b) model simulation. Shown in (c) is the power spectrum of the effective solar radiation. The time series were normalized prior to the spectrum analyses. The solid line denotes the spectrum. The dashed line denotes the least-squares best fit of a theoretical red-noise spectrum (i.e. the Markov "red-noise" spectrum).

but strong during the LIA. The simulated PDO generally varies in parallel with the reconstruction, which has a negative phase during the MWP and a positive phase during the LIA. The correlation coefficient between the reconstruction and simulation is 0.61 , and the correlation is statistically significant at the $1 \%$ level. The consistency between the simulation and reconstruction suggests that external forcings may have played significant roles in the centennial PDO variations during the last millennium. In addition, the negative PDO phase during the MWP may lead to strong 

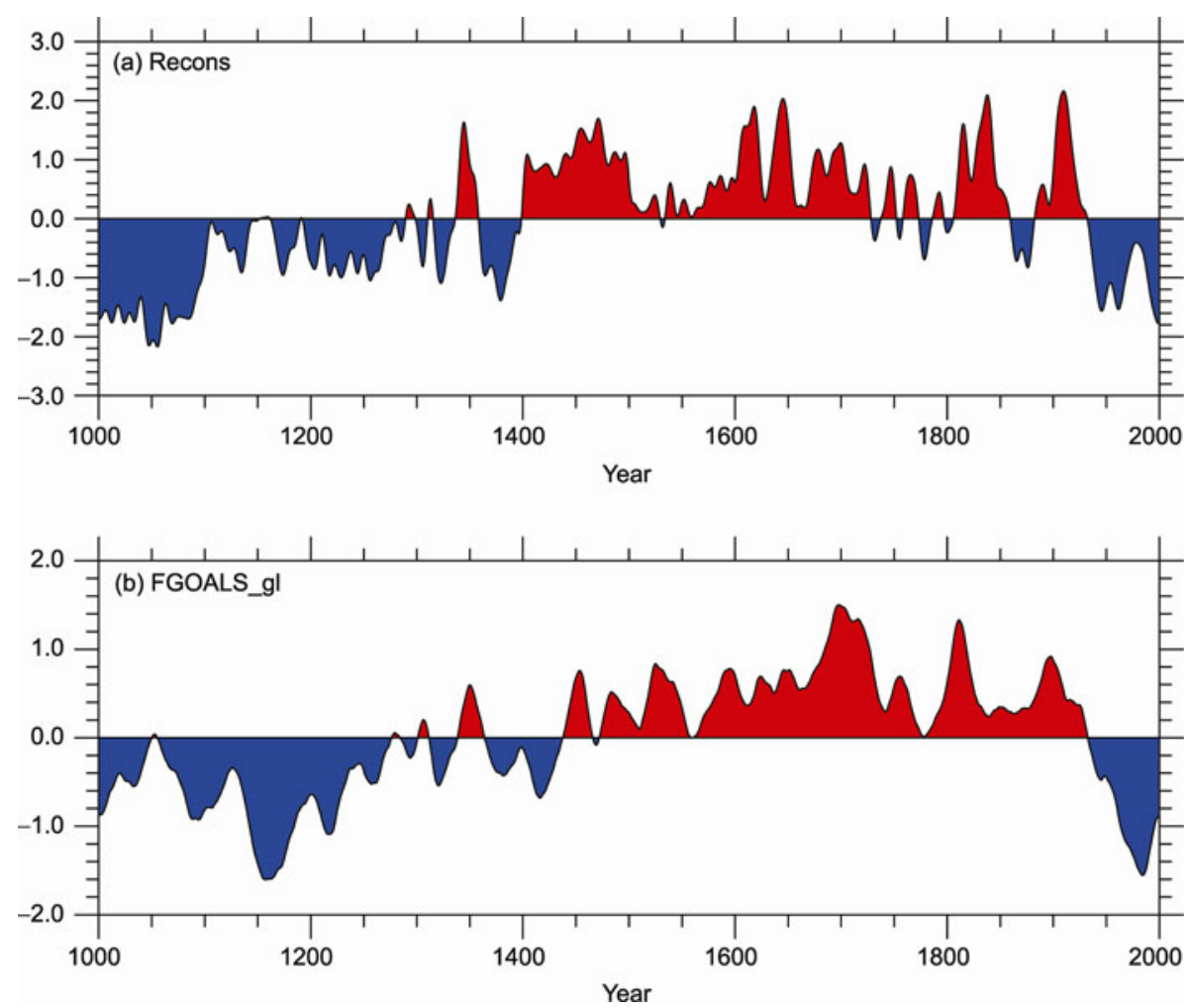

Figure 3 PDO variations during the last millennium derived from (a) reconstruction and (b) model simulation. The time series were smoothed with a 31-year low-pass filter. The anomalies were calculated relative to the millennial mean.

EASM circulation, while the positive PDO phase during the LIA may lead to weak EASM circulation.

The power spectra of the reconstructed and simulated PDO series are presented in Figure 4. Dominant spectral peaks at $180,90-110$ and $50-70$ years are seen in the reconstructed PDO series (Figure 4(a)). The leading spectral peak is 200 years in the simulated PDO series. At centennial and multi-decadal time scales, prominent peaks at 90-120 years and 50-70 years are evident in the simulation (Figure 4(b)). This generally corresponds to the spectral peaks of specified effective solar radiation forcings. The coherent spectral peaks support the effects of external forcings on the PDO.

\subsection{ENSO}

The ENSO, originating from the tropical Pacific, is the strongest mode of global air-sea interaction and has been regarded as a major factor modulating atmospheric circulation and climate on interannual timescales [39]. Studies have also indicated that the ENSO plays a key role in the interannual variability of temperature and summer rainfall over China [40-43]. There is generally excessive precipitation over eastern China along the Yangtze River valley but deficient rainfall in both North and South China during an El Niño decaying summer $[44,45]$. Previous studies focused on the interannual variability of the ENSO, and the behavior of ENSO variability on decadal-centennial time scales and its possible influence on climate during the last millennium are largely unknown.

The reconstructed and simulated Niño-3 indexes for the last millennium are shown in Figure 5. A 31-year low-pass filter has been applied to both time series. The proxy data indicate that there was a La Niña-like state in the MWP and an El Niño-like state in the LIA. This phenomenon is particularly obvious in the 15th, 17th and 19th centuries. However, neither the La Niña-like state of the MWP nor the El Niño-like state in the LIA is reproduced in the model. Previous studies have suggested that the reconstructed $\mathrm{La} \mathrm{Ni}$ ña-like condition in the MWP arises from different surface temperature responses in the eastern and western Pacific, the mechanism of which is as follows [46]. In the western Pacific, where the thermocline is deep, the response to surface heating is largely thermodynamic and the mixed layer adjusts with an increase in temperature; in the eastern Pacific, where the thermocline is shallow, the cooling induced by vertical advection offsets the surface heating, resulting in a smaller temperature response. The increased zonal SST gradient accelerates the trade winds, which leads to further cooling by vertical advection in the eastern Pacific, and further acceleration of winds through the Bjerknes feedback. This response is referred to as being La Niña-like and the reverse pattern of response to cooling as solar radiation reduces is referred to as being El Niño-like. However, the feedbacks governing the above responses are not reasonably 

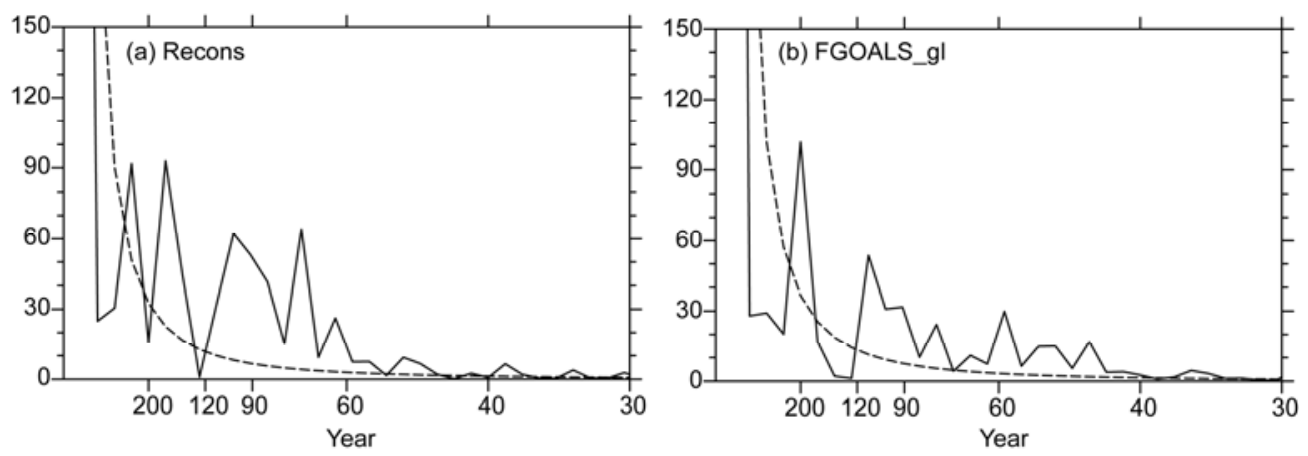

Figure 4 Power spectra of the PDO index derived from (a) reconstruction and (b) model simulation. The time series were normalized prior to the spectrum analyses. The solid line denotes the spectrum. The dashed line denotes the least-squares best fit of a theoretical red-noise spectrum (i.e. the Markov "red-noise" spectrum).
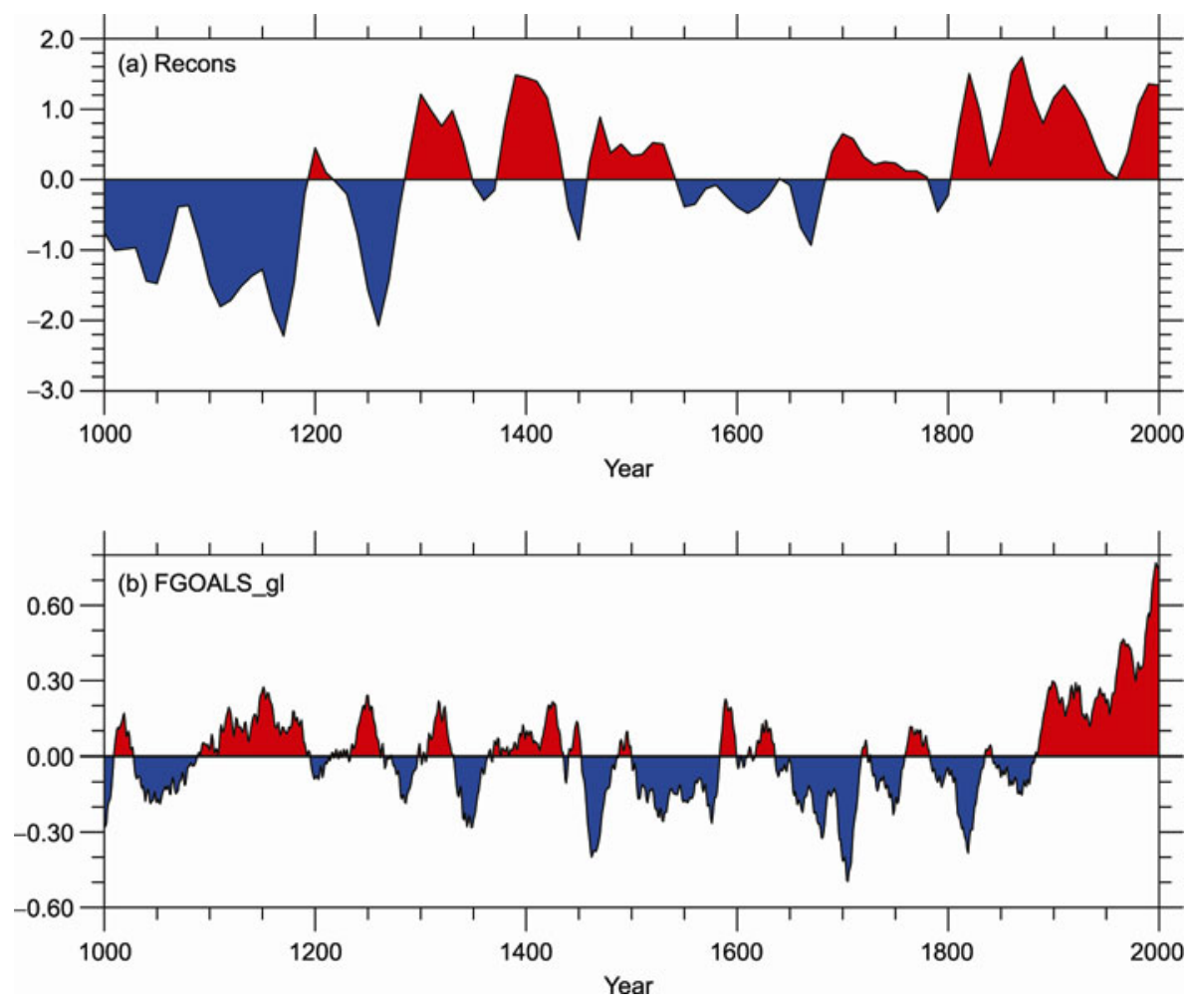

Figure 5 Niño-3 index during the last millennium derived from (a) reconstruction and (b) model simulation. The time series has been smoothed with a 31-year low-pass filter. The anomalies were calculated relative to the millennial mean.

represented in coarser-resolution global coupled models [47]. Previous studies employing the simplified ZebiakCane model of the tropical Pacific coupled ocean-atmosphere system have reproduced the potential response of the ENSO to anomalous radiative forcing, including the La Niña-like pattern of the MWP and the El Niño-like pattern of the LIA [46].

To reveal the decadal-centennial variability of the ENSO during the last millennium, the power spectra of the reconstructed and simulated Niño-3 indexes are shown in Figure 6. Significant peaks at 100,80 and 50 years are seen in the reconstruction (Figure 6(a)). The spectrum of the simulated Niño-3 series has pronounced peaks of bicentennial and centennial time scales around 200 and 120 years and multidecadal time scales around 50-70 years (Figure 6(b)). This corresponds well to the spectral peaks of specified effective radiative forcing. The coherence indicates that effective solar radiation forcings played a significant role in the decadal-centennial variability of the ENSO.

\subsection{AAO}

The AAO is the major mode of atmospheric circulation over mid-high latitudes of the Southern Hemisphere. It refers to a large-scale alternation of surface atmospheric pressure between mid-latitudes and high latitudes $[48,49]$. The AAO 

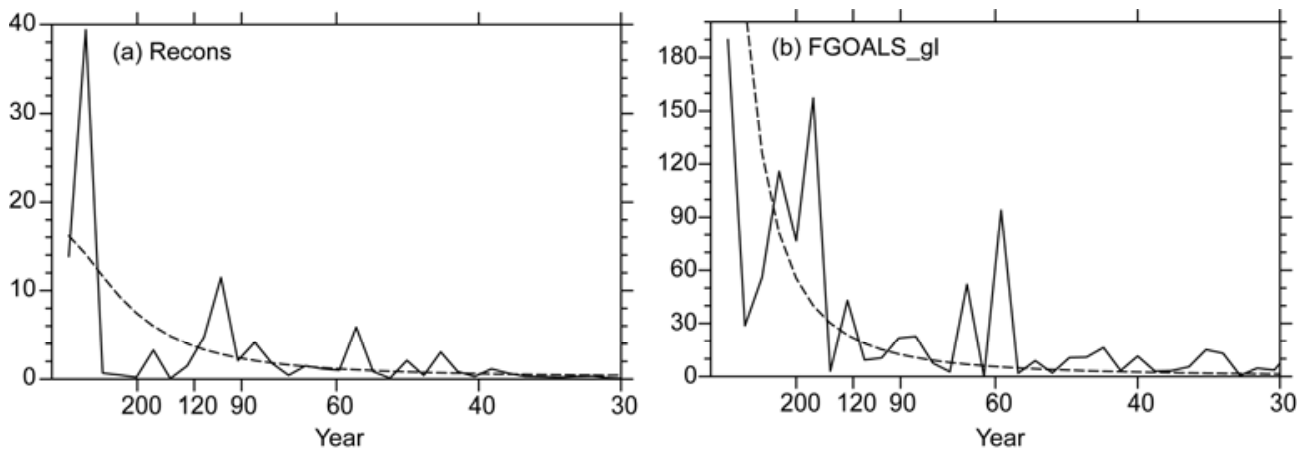

Figure 6 Power spectra of the Niño-3 index derived from (a) reconstruction and (b) model simulation. The time series were normalized prior to the spectrum analyses. The solid line denotes the spectrum. The dashed line denotes the least-squares best fit of a theoretical red-noise spectrum (i.e. Markov "red-noise" spectrum).

index is defined as the difference in zonal mean sea-level pressure between $40^{\circ} \mathrm{S}$ and $65^{\circ} \mathrm{S}$ [27]. Anomalous AAO behavior would lead to deficient or excessive precipitation along the Yangtze River and Huaihe River Valleys. During the positive phases of the spring AAO, the EASM is generally weak and there is excessive precipitation along the Yangtze River and Huaihe River Valleys. The regimes are opposite during the negative phases [50].

The reconstructed and simulated AAO series for the last millennium are shown in Figure 7. The reconstructed AAO is generally weak during the MWP (except for a discontinuity during 1250-1300 AD) and strong during the LIA. The model generally well reproduces the negative phase of the
AAO in the early stage of the last millennium and the positive phase in the late stage of the last millennium. The negative AAO phase during the MWP would lead to strong EASM circulation, while the positive AAO phase during the LIA would lead to weak EASM circulation.

To reveal the dominant time scales of the AAO during the last millennium, the power spectra for the reconstructed and simulated AAO indexes are shown in Figure 8. Significant peaks of bicentennial and centennial time scales around 200 and 100 years and multi-decadal time scales around 80 years are seen in the reconstruction (Figure 8(a)). The spectrum of the simulated AAO series has pronounced peaks of bicentennial and centennial time scales around 200 and 110
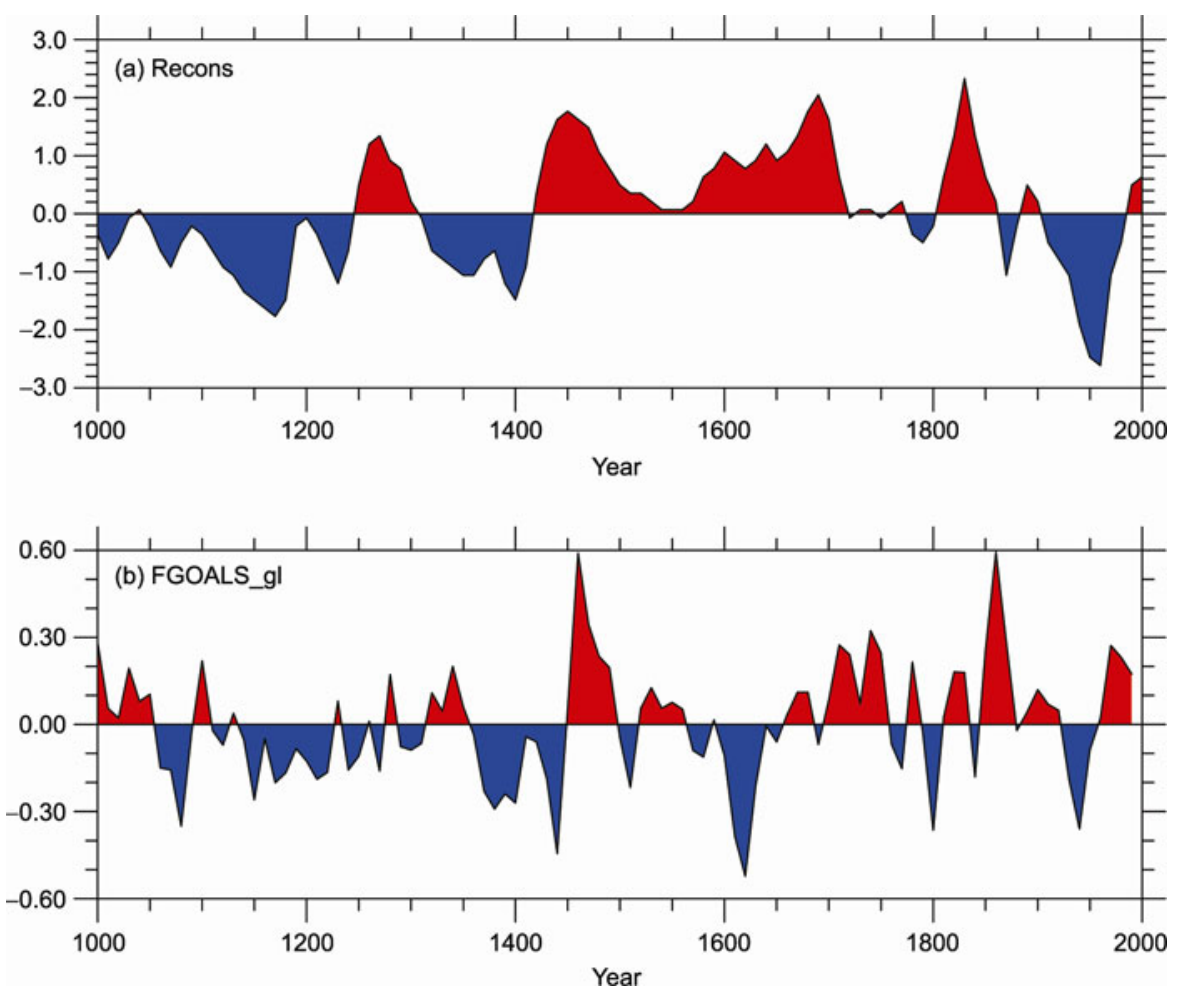

Figure 7 AAO variations during the last millennium derived from (a) reconstruction and (b) model simulation. The time series were smoothed with a 31-year low-pass filter. The anomalies were calculated relative to the millennial mean. 

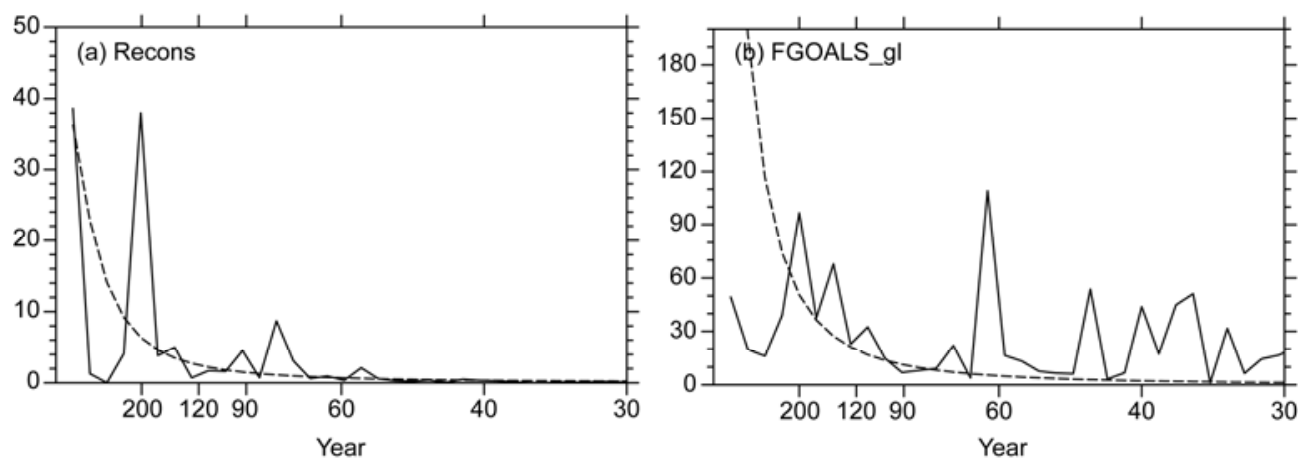

Figure 8 Power spectra of the AAO index derived from (a) reconstruction and (b) model simulation. The time series were normalized prior to the spectrum analyses. The solid line denotes spectrum. The dashed line denotes the least-squares best fit of a theoretical red-noise spectrum (i.e. Markov "red-noise" spectrum).

years and multi-decadal time scales around 70 and 50 years (Figure 8(b)). The coherence also indicates that the decadal-centennial AAO variations during the last millennium were partly driven by effective radiative forcing.

\subsection{APO}

In addition to the four global atmospheric oscillations, Zhao et al. [28] defined the APO as a zonal teleconnection pattern over the extratropical Asian-Pacific region, which measures the zonal thermal contrast between the Asian continent and the Pacific Ocean. The APO is actually a local manifestation of the asymmetric zonal change in the tropospheric temperature in the Northern Hemisphere based on the works of Zhou and Zhang [51], and Zhou et al. [52]. EASM variability is a consequence of the land-sea thermal contrast between Asia and the adjacent ocean; thus, it is appropriate to investigate the long-term variations of the EASM using the APO over the last millennium. Previous studies have indicated that the APO well represents the EASM and rainfall anomalies over eastern China on interannual, decadal and centennial scales [28,31].

The reconstructed and simulated APO indexes during the last millennium are shown in Figure 9. The reconstructed APO index tended to be positive during the MWP and negative during the LIA (especially during 1420-1625 AD), and was lowest in 1450-1570 AD. The simulation features a prominent enhanced APO during 1000-1400 AD and a
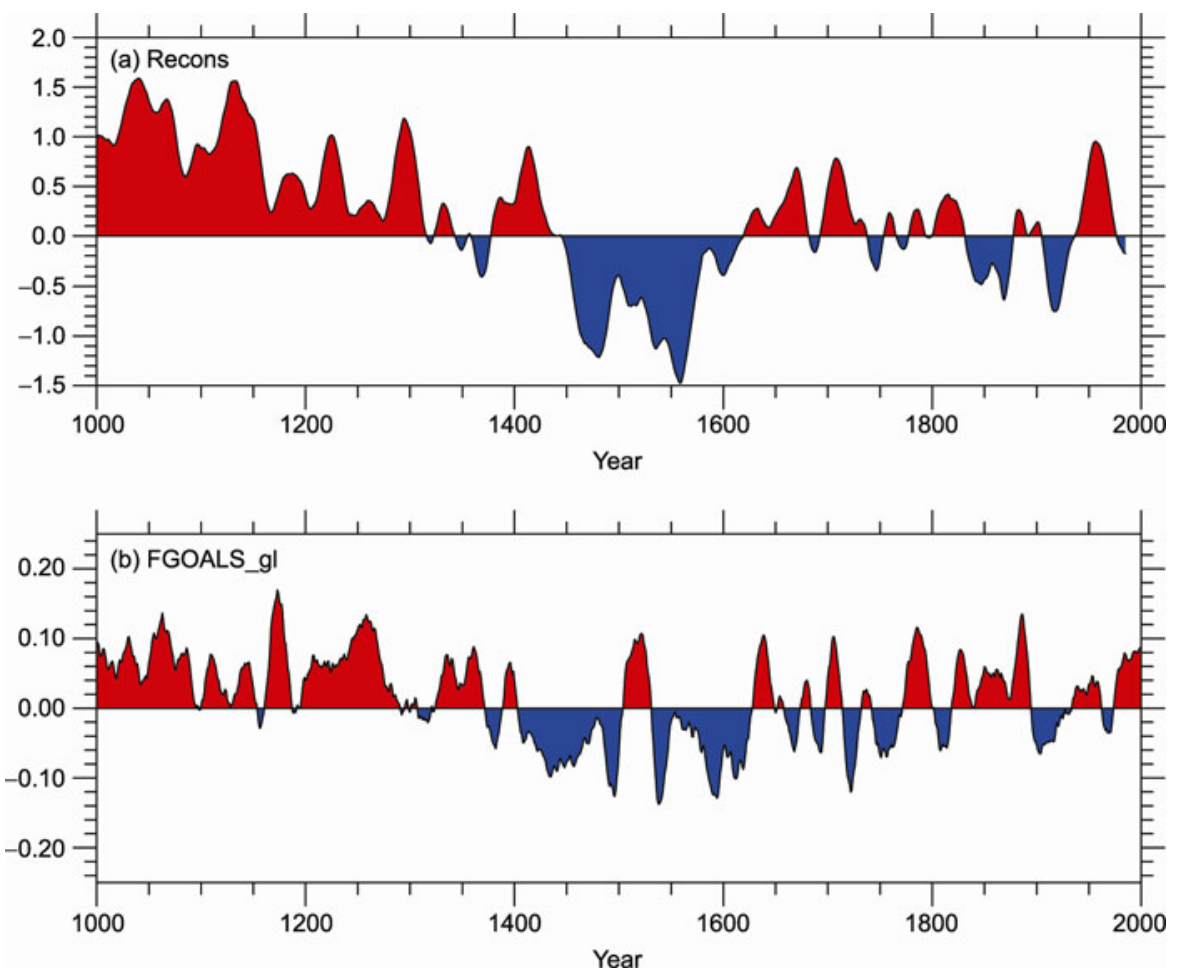

Figure 9 APO variations during the last millennium derived from (a) reconstruction and (b) model simulation. The time series were smoothed with a 31-year low-pass filter. The anomalies were calculated relative to the millennial mean. 

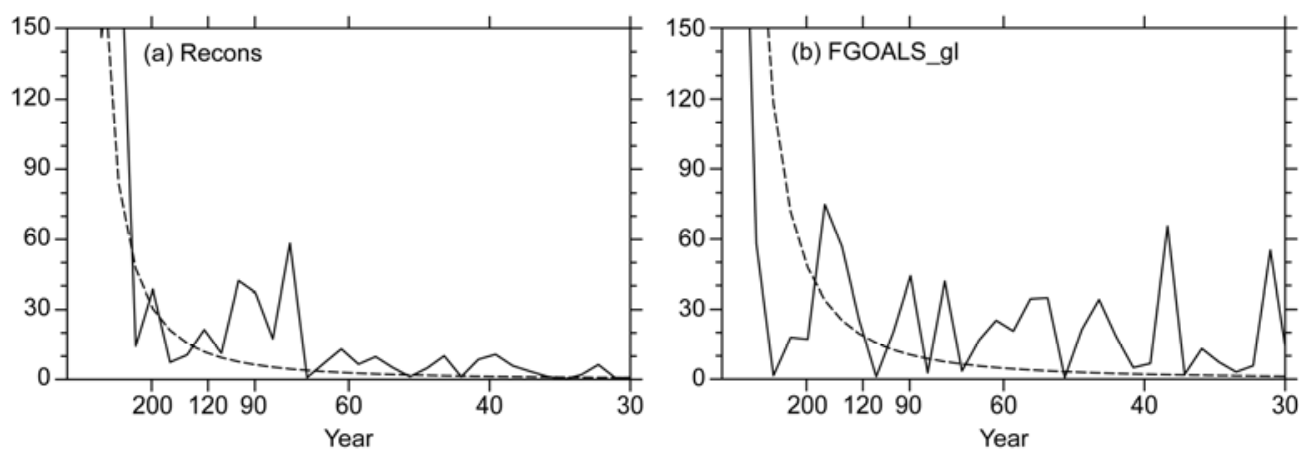

Figure 10 Power spectra of the APO index derived from (a) reconstruction and (b) model simulation. The time series were normalized prior to the spectrum analyses. The solid line denotes the spectrum. The dashed line denotes the least-squares best fit of a theoretical red-noise spectrum (i.e. Markov "red-noise" spectrum).

weakening from 1400 to 1625 AD (except for a short discontinuity during 1500-1520 AD). The correlation coefficient between the reconstruction and simulation during $1000-1985 \mathrm{AD}$ is 0.50 , and the correlation is statistically significant at the $1 \%$ level. Zonal thermal contrast between Asia and the North Pacific is seen for the summer tropospheric mean (taken over 200-500 hPa) temperature anomalies (figure not shown). The higher and lower tropospheric temperatures over Eurasia and the extra-tropical North Pacific reflect a stronger APO index during the MWP. The regimes were opposite during the LIA. The consistently negative APO index in both the reconstruction and simulation during 1450-1570 AD indicates that the thermal contrast between Asia and the North Pacific is weaker, corresponding to a weak EASM. The thermal contrast between Asia and the North Pacific is enhanced after 1650 AD, resulting in a stronger EASM.

The power spectra of the reconstructed and simulated APO indexes are shown in Figure 10. Significant peaks of bicentennial and centennial time scales around 200 and 100 years and multi-decadal time scales around 80 years are seen in the reconstruction (Figure 10(a)). The spectrum of the simulated APO series has pronounced peaks of bicentennial and centennial time scales around 200 and 100 years and multi-decadal time scales around 80 and 30-50 years (Figure 10(b)). The coherence indicates that the APO variations during the last millennium were driven primarily by effective radiative forcing through the land-sea thermal contrast between Asia and the North Pacific.

\section{Summary and discussion}

In this study, the global atmospheric oscillation variations during the past millennium are simulated using LASG/IAP climate system model. The model results are compared with reconstruction data. The main results are summarized as follows.

(1) The model generally reproduces the positive phase of the NAO during 1000-1400 AD and the negative phase during 1650-1900 AD. However, the simulated NAO index during 1400-1650 AD is out of phase with the reconstruction.

(2) The simulated PDO index generally varies in parallel with the reconstruction, which has a negative phase during the MWP and a positive phase during the LIA. The correlation coefficient between the reconstruction and simulation is 0.61 , and the correlation is statistically significant at the $1 \%$ level.

(3) The reconstruction indicates that there was a $\mathrm{La} \mathrm{Ni}$ ña-like state in the MWP and an El Niño-like state in the LIA. This phenomenon is particularly obvious in the 15 th, 17 th and 19th centuries. However, neither the La Niña-like pattern of the MWP nor the El Niño-like pattern of the LIA is reproduced in the model.

(4) The reconstructed AAO index was generally negative during the MWP and positive during the LIA. The model generally reproduces the negative phase of the AAO in the early stage of the last millennium and the positive phase in the late stage of the last millennium.

(5) The model reasonably reproduces the strong APO phase during the MWP and the weak phase during the LIA. The correlation coefficient between the reconstruction and simulation during $1000-1985 \mathrm{AD}$ is 0.50 , which is statistically significant at the $1 \%$ level.

Nearly all the reconstructed and simulated atmospheric oscillations have coherent peaks at centennial time scales around 90-120 years and multi-decadal time scales around 50-80 years, which generally correspond to the spectral peaks of specified effective solar radiation forcings. The consistency suggests that the specified external forcings have had significant roles in the evolution of global atmospheric circulations over the past millennium. The crossspectrum analysis also indicates that there are coherent peaks of 50-80 years for the atmospheric oscillations and the effective radiative forcing (figure not shown here), further demonstrating the effects of the external forcings on the 50-80-year oscillations. However, previous studies have suggested that the internal variability of the coupled climate system may also generate a 50-80-year oscillation [53,54]. 
Therefore, both the external forcing and the internal variability of the climate system appear to generate 50-80-year atmospheric oscillations. How to distinguish the contributions from external forcing and internal variability requires further study.

This work was supported by the National Natural Science Foundation of China (40890054) and the National Key Technology R\&D Program of China (2007BAC29B03).

1 Huang J B, Wang S W, Gong D Y, et al. Atmospheric oscillations over the last millennium. Chinese Sci Bull, 2010, 55: 2469-2472

2 Cobb K M, Charles C D, Cheng H, et al. El Niño/Southern Oscillation and tropical Pacific climate during the last millennium. Nature, 2003, 424: 271-276

3 Trouet V, Esper J, Graham N E, et al. Persistent positive North Atlantic Oscillation mode dominated the Medieval Climate Anomaly. Science, 2009, 324: 78-80

4 MacDonald G M, Case R A. Variations in the Pacific Decadal Oscillation over the past millennium. Geophys Res Lett, 2005, 32: L08703

5 Fu C B, Zeng Z M. Relationships between winter North Atlantic Oscillation (NAO) index and summer drought/flood (D/F) index over East China (in Chinese). Chinese Sci Bull (Chinese Ver), 2005, 50: 1512-1522

6 Shen C M, Wang W C, Gong W, et al. A Pacific Decadal Oscillation record since $1470 \mathrm{AD}$ reconstructed from proxy data of summer rainfall over eastern China. Geophys Res Lett, 2006, 33: L03702

7 Zhou T J, Man W M, Zhang J. Progress in numerical simulations of the climate over the last millennium (in Chinese). Adv Earth Sci, 2009, 24: 469-476

8 Bertrand C, Loutre M-F, Crucifix M, et al. Climate of the last millennium: A sensitivity study. Tellus, 2002, 54A: 221-244

9 Bauer E, Clausse M, Brovkin V, et al. Assessing climate forcings of the Earth system for the past millennium. Geophys Res Lett, 2003, 30: 1276

10 Goosse H, Renssen H, Timmermann A, et al. Internal and forced climate variability during the last millennium: A model-data comparison using ensemble simulations. Quat Sci Rev, 2005, 24: 1345-1360

11 Zorita E, Gonzalez-Rouco J F, von Storch H, et al. Natural and anthropogenic modes of surface temperature variations in the last thousand years. Geophys Res Lett, 2005, 32: L08707

12 Osborn T J, Raper S C B, Briffa K R. Simulated climate change during the last 1000 years: Comparing the ECHO-G general circulation model with the MAGICC simple climate model. Clim Dyn, 2006, 27: 185-197

13 Yoshimori M, Stocher T F, Raible C C, et al. Externally forced and internal variability in ensemble climate simulations of the Maunder Minimum. J Clim, 2005, 18: 4253-4268

14 Zhou T J, Wu B, Wen X Y, et al. A fast version of LASG/IAP climate system model and its 1000-year control integration. Adv Atmos Sci, 2008, 25: 655-672

15 Man W M, Zhou T J, Zhang L X. The tropical Pacific interannual variability simulated by LASG/IAP climate system model FGOALS_gl (in Chinese). Chin J Atmos Sci, 2010, 34: 1141-1154

16 Zhang J, Zhou T J, Man W M, et al. The transient simulation of Little Ice Age by LASG/IAP climate system model (in Chinese). Quat Sci, 2009, 29: 1125-1134

17 Man W M, Zhou T J, Zhang J, et al. The equilibrium response of LASG/IAP climate system model to prescribed external forcing of Little Ice Age (in Chinese). Chin J Atmos Sci, 2010, 34: 914-924

18 Zhou T J, Li B, Man W M, et al. A comparison of the Medieval Warm Period, the Little Ice Age and the 20th century warming simulated by FGOALS climate system model. Chinese Sci Bull, 2011, 56: 3028-3041

19 Man W M, Zhou T J, Zhang J, et al. The 20th century climate simulated by LASG/IAP climate system model FGOALS_gl (in Chinese).
Acta Meteorol Sin, 2011, 69: 644-654

20 Liu H, Zhang X, Li W, et al. An eddy-permitting oceanic general circulation model and its preliminary evaluations. Adv Atmos Sci, 2004, 21: 675-690

21 Crowley T J. Causes of climate change over the past 1000 years. Science, 2000, 289: 270-277

22 Ammann C M, Joos F, Schimel D S, et al. Solar influence on climate during the past millennium: Results from transient simulations with the NCAR Climate System Model. Proc Natl Acad Sci USA, 2007, 104: 3713-3718

23 Zhang J. General features of climate changes during the last 1000 years in a climate system model. Dissertation for the Doctoral Degree. Paris: L'Universite Pierre et Marie Curie, 2010. 8-9

24 Hurrell J W, Kushnir Y, Ottersen G, et al. An overview of the North Atlantic Oscillation. In: Hurrell J W, ed. The North Atlantic Oscillation: Climatic Significance and Environmental Impact. Geophysical Monograph. Washington, D C: American Geophysical Union, 2003. $1-35$

25 Mantua N J, Hare S R, Zhang Y, et al. A Pacific interdecadal climate oscillation with impacts on Salmon. Bull Am Meteorol Soc, 1997, 78: 1069-1079

26 Wittenberg A T, Rosati A, Lau N C, et al. GFDL's CM2 coupled climate models. Part II: Tropical pacific climate and ENSO. J Clim, 2006, 19: 698-722

27 Gong D Y, Wang S W. Definition of Antarctic oscillation index. Geophys Res Lett, 1999, 26: 459-462

28 Zhao P, Zhu Y N, Zhang R H. An Asia-Pacific teleconnection in summer tropospheric temperature and associated Asian climate variability. Clim Dyn, 2007, 29: 293-303

29 Diaz H F, Pulwarty R S. An analysis of the time scales of variability in centuries-long ENSO-sensitive records in the last 1000 years. Clim Change, 1994, 26: 317-342

30 Mayr C, Wille M, Haberzettl T, et al. Holocene variability of the Southern Hemisphere westerlies in Argentinean Patagonia $\left(52^{\circ} \mathrm{S}\right)$. Quat Sci Rev, 2007, 26: 579-584

31 Zhou X J, Zhao P, Liu G. Asian-Pacific Oscillation index and variation of East Asian summer monsoon over the past millennium. Chinese Sci Bull, 2009, 54: 3768-3771

32 Luterbacher J, Schmutz C, Gyalistras D, et al. Reconstruction of monthly NAO and EU indices back to AD 1675. Geophys Res Lett, 1999, 26: 2745-2748

33 Glueck M F, Stockton C W. Reconstruction of the North Atlantic Oscillation, 1429-1983. Int J Climatol, 2001, 21: 1453-1465

34 Cook E R, D'arrigo R D, Mann M E. A well-verified, multiproxy reconstruction of the winter North Atlantic Oscillation index since A.D. 1400. J Clim, 2002, 15: 1754-1764

35 Shindell D T, Schmidt G A, Mann M E, et al. Solar forcing of regional climate change during the Maunder Minimum. Science, 2001, 294: 2149-2152

36 Wang H J. The weakening of the Asian monsoon circulation after the end of 1970s. Adv Atmos Sci, 2001, 18: 374-386

37 Wang $\mathrm{H}$ J. The instability of the East Asian summer monsoon-ENSO relations. Adv Atmos Sci, 2002, 19: 1-11

38 Zhu Y M, Yang X Q. Relationships between Pacific Decadal Oscillation (PDO) and climate variabilities in China (in Chinese). Acta Meteorol Sin, 2003, 61: 641-654

39 Alexander M A, Blade I, Newman M, et al. The atmospheric bridge: The influence of ENSO teleconnections on air-sea interaction over the global ocean. J Clim, 2002, 15: 2205-2231

$40 \mathrm{Wu} \mathrm{B}$, Zhou T J. Oceanic origin of the interannual and interdecadal variability of the summertime western Pacific subtropical high. Geophys Res Lett, 2008, 35: L13701

41 Wu B, Zhou T J, Li T M. Seasonally evolving dominant interannual variability modes of East Asian Climate. J Clim, 2009, 22: 29923005

42 Wang B, Liu J, Yang J, et al. Distinct principal modes of early and late summer rainfall anomalies in East Asia. J Clim, 2009, 22: 3864-3875

43 Zhou T J, Wu B, Wang B. How well do Atmospheric General Circu- 
lation Models capture the leading modes of the interannual variability of Asian-Australian Monsoon? J Clim, 2009, 22: 1159-1173

44 Huang R H, Wu Y F. The influence of ENSO on the summer climate change in China and its mechanism. Adv Atmos Sci, 1989, 6: 26-37

45 Gong D Y, Wang S W. Impact of ENSO on the seasonal rainfall in China (in Chinese). J Nat Dis, 1999, 7: 44-52

46 Mann M E, Cane M A, Zebiak S E, et al. Volcanic and solar forcing of the tropical Pacific over the past 1000 years. J Clim, 2005, 18: $447-456$

47 Latif M, Sperber K, Arblaster J, et al. ENSIP: The El Niño simulation intercomparison project. Clim Dyn, 2001, 18: 255-276

48 Rogers J R, Van L H. Spatial variability of sea level pressure and 500 mb height anomalies over the Southern Hemisphere. Mon Weather Rev, 1982, 110: 1375-1392

49 Mo K C, White G N. Teleconnections in the Southern Hemisphere.
Mon Weather Rev, 1985, 113: 22-37

50 Gao $\mathrm{H}$, Xue F, Wang $\mathrm{H} \mathrm{J}$. The influence of the interannual variability of AAO on Meiyu in the Jiang-Huai Valleys and its forecast significance (in Chinese). Chinese Sci Bull (Chinese Ver), 2003, 48: 87-92

51 Zhou T J, Zhang J. Harmonious inter-decadal changes of July-August upper tropospheric temperature across the North Atlantic, Eurasian continent, and North Pacific. Adv Atmos Sci, 2009, 26: 656-665

52 Zhou T, Gong D, Li J, et al. Detecting and understanding the multidecadal variability of the East Asian Summer Monsoon? Recent progress and state of affairs. Meteorol Zeitschrift, 2009, 18: 455-467

53 Tanimoto Y N, Iwasaka N, Hanawa K, et al. Characteristic variations of sea surface temperature with multiple time scales in the North Pacific. J Clim, 1993, 6: 1153-1160

54 Kerr R A. A North Atlantic climate pacemaker for the centuries. Science, 2000, 288: 1984-1985

Open Access This article is distributed under the terms of the Creative Commons Attribution License which permits any use, distribution, and reproduction in any medium, provided the original author(s) and source are credited. 